\title{
Osteoid Osteoma of the Ribs - Is Image Intensifier or Bone Scintigraphy a Man- datory Diagnostic Tool - A Case report with Review of Literature
}

\author{
Nagre $S^{*}{ }^{*}$ and Paul $S^{2}$
}

${ }^{1}$ Associate Professor, Department of CVTS, Grant Medical College, Mumbai, India

${ }^{2}$ Senior Resident, Grant medical college, Mumbai, India

*Corresponding author: Nagre SW, 31, Trimurti Building, J J Hospital compound, Byculla, Mumbai, India, 400008, Tel: 09967795303, E-mail: surajnagre@yahoo.com

Citation: Nagre SW, Paul S (2018) Osteoid Osteoma of the Ribs - Is Image Intensifier or Bone Scintigraphy a Mandatory Diagnostic Tool - A Case report with Review of Literature. J Respir Dis Treat 1(1): 101.

doi: $10.15744 / 2767-4649.1 .101$

Received Date: February 18, 2018 Accepted Date: April 13, 2020 Published Date: April 15, 2020

\begin{abstract}
Osteoid osteoma (OO) is a benign bone tumour. In 1935, the jaffe reported it first. The fifty percent of OOs occur in lone bones of the lower extremities but it may affect any bone. Only $1 \%$ OOs affects the ribs and surgical excision was reported only in 14 cases in literature. Complete surgical excision is the standard treatment method for osteoid osteoma is complete surgical excision which is reserved for the patients not responding to conservative treatment. In this report we present a case of osteoid osteoma of the posterior part of the shaft of the sixth rib affecting a 30 year old male, who had presented with symptoms of severe pain over the affected area and underwent surgical resection. Excised rib segment showed no osteosclerotic lesion on X ray so immediately extended resection of sixth rib was done. Here we have tried to evaluate the importance of the presence of the skeletal scintigraphy or C Arm image intensifier intra operatively by comparing our experience with the available literature.

Keywords: Osteoid osteoma; Rib; Image intensifier

List of abbreviations: OO: Osteoid osteoma; NSAID: Non-steroidal anti-inflammatory drugs; CT: Computarised Tomogram
\end{abstract}

\section{Introduction}

Osteoid osteoma is a type of benign bone tumor, which was first described by Jaffe in 1935 [1]. It is a rare condition, which accounts for only 10 to $12 \%$ of primary bone tumors. The most commonly affected sites are the long bones of the lower extremities and the rib involvement is seen in less than 3\% [3]. Individuals aged between 5 and 24 years old are the most commonly affected [2]. The main symptom of the rib $\mathrm{OO}$ is pain that worsens at night, which may be alleviated by NSAIDs. On chest X ray it looks as osteosclerotic lesion in rib but CT scan has better sensitivity than X ray. Current treatment modalities include surgical excision, as well as less invasive techniques like alcohol ablation. Difficulty during surgery is lesion localisation for which intraopt use of C arm or histopathological examination of excised rib specimen is helpful.

\section{Case Report}

A 30-year-old male admitted to our ward with history of persistent pain posteriorly on left side in chest since two years. He was treated with NSAIDs for one year by his doctor. Now the pain was not relieved by medications so he came to us for further management. At the initial visit to our hospital, there was no local tenderness, swelling, or redness, but the patient complained of severe pain over the left side of the back, inferior to the left scapula. A plain radiograph showed mild bone sclerosis of the posterior part of the left $6^{\text {th }}$ rib. CT examinations revealed a small $(6 \times 6 \mathrm{~mm})$ well demarcated osteosclerotic lesion in the posterior end of the left $6^{\text {th }}$ rib; minimal periosteal reaction was noted along the rib (Figure 1). No centrally calcified nidus was noted.
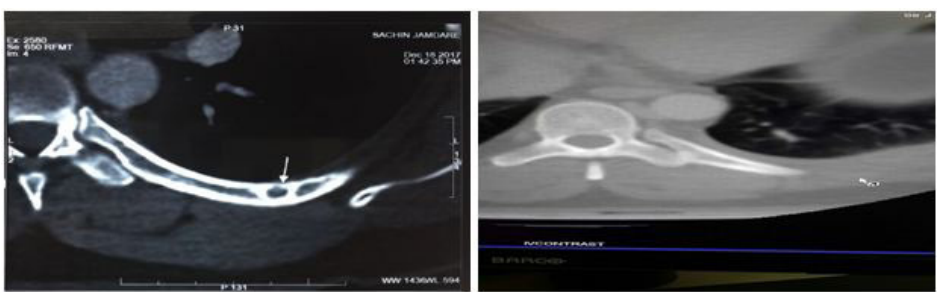

Figure 1: a. Small (6x6 mm) well demarcated osteosclerotic lesion in the posterior end of the left $6^{\text {th }}$ rib in propt CT scan $\mathbf{b}$. Post opt CT scan 
Pre-operative suspicion was strongly of that of an osteoid osteoma. The patient was taken up for surgery and under GA through posterior minithoracotomy posterior segment of sixth rib was excised (Figure 2a).
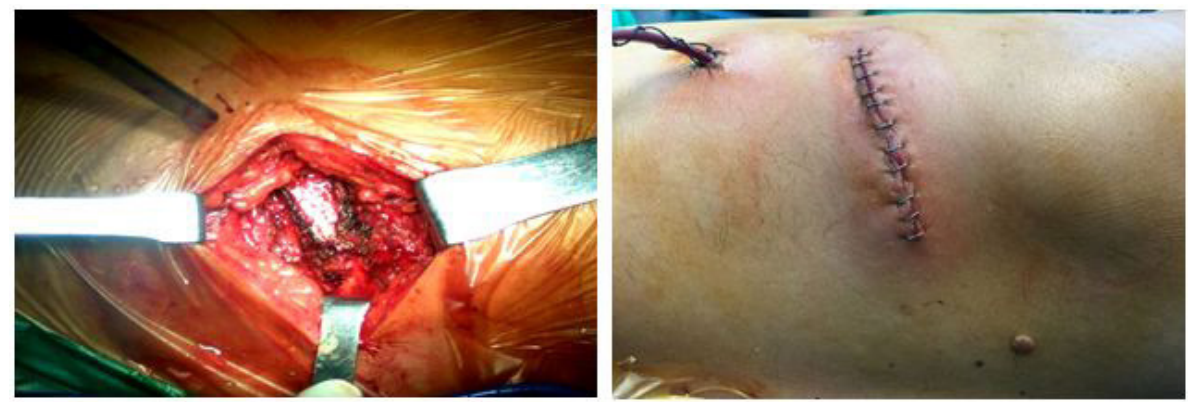

Figure 2: a. Intra Operative sixth rib $\quad$ b. After closure of incision

The excised portion of the $6^{\text {th }}$ rib was sent for X ray, however no osteosclerotic lesion was present in that (Figure 3a). So, immediately extended resection involving the $6^{\text {th }}$ and $7^{\text {th }}$ ribs was done. The resected $7^{\text {th }}$ rib showed the osteosclerotic lesion this time on $\mathrm{X}$ ray (Figure 3b).
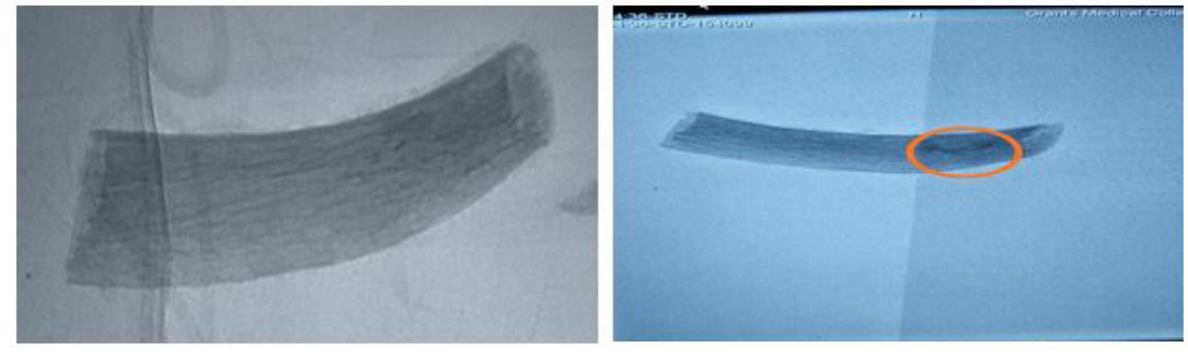

Figure 3: a. No osteosclerotic lesion 6 rib b. Osteosclerotic lesion seen 7 rib

Incision closed in layers after keeping negative suction drain (Figure2b). Patient extubated and shifted to ward. The resected bone segments of both sixth and seventh rib externally looked same (Figure $4 \mathrm{a}$ and $4 \mathrm{~b}$ ) so we sent them for histopathological examination.
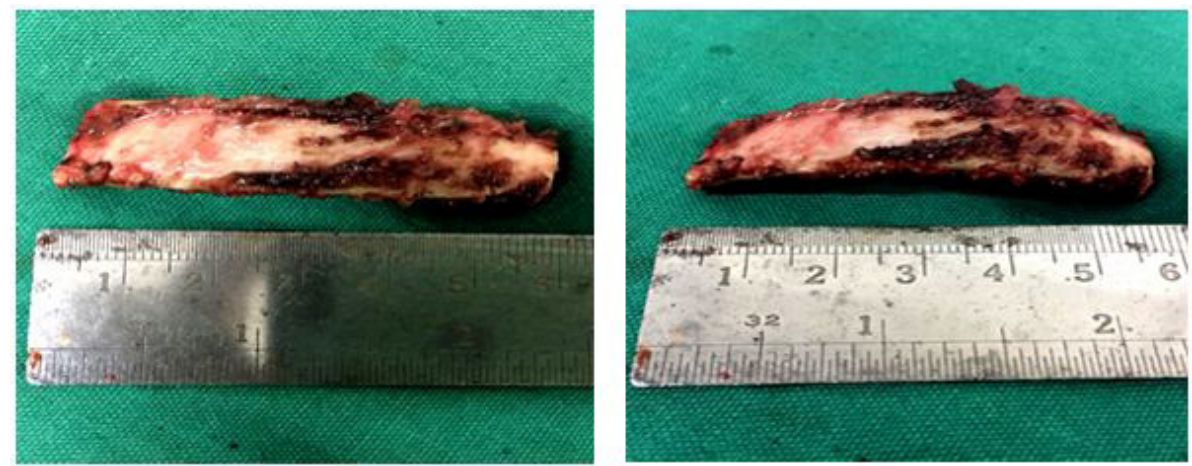

Figure 4: Resected rib segments a. Sixth rib b. Seventh rib

Post operatively patient was comfortable. Chest X ray done and compared with preopt Chest X ray (Figure 5a and 5b). Drain removed after 48 hours and patient was discharged on fifth postopt day. Stich removal was done on fifteenth postopt day.
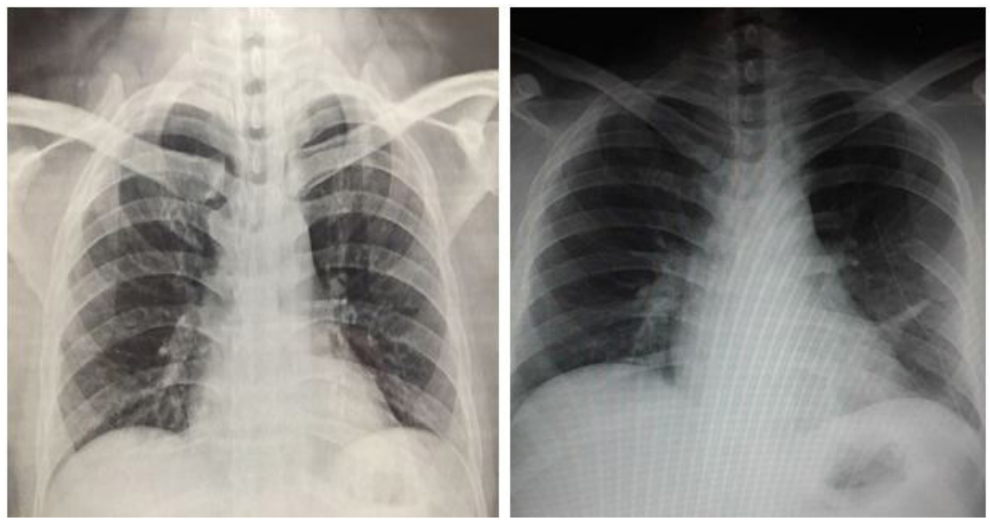

Figure 5: Chest X ray a. Preopt b. Postopt 
Histopathological examination of sixth rib was normal but seventh rib revealed the presence of osteoid tissue in a background stroma of fibrovascular tissue and thin trabeculae inter-anastomosing with a single layer of osteoblasts (Figure 6).
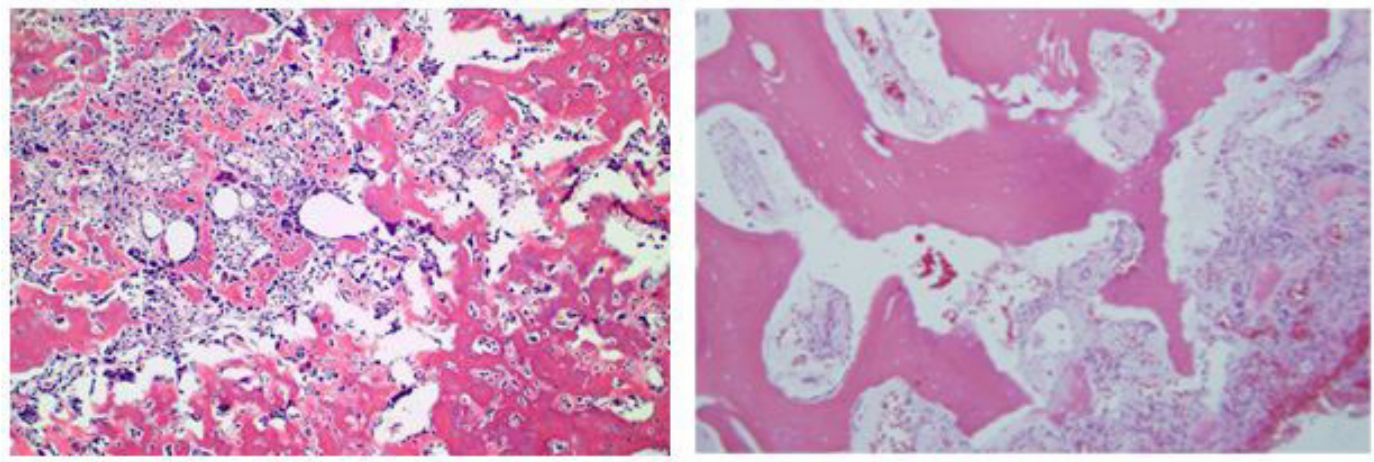

Figure 6: Histopath seventh rib under low and high power

\section{Discussion}

On CT scan Osteoid osteomas looks as well-demarcated core of size less than $1 \mathrm{~cm}$ with surrounding zone of reactive bone formation [2-16]. The pain of osteoid osteoma worsens in the night and responds well to nonsteroidal anti inflammatory drugs. The posterior or posterolateral shaft of the rib is common site of OOs. Scoliosis can occur if the osteoid osteoma is in rib near the spine [17]. On Imaging it looks as a small radiolucent lesion with a thick sclerotic margin of reactive bone. CT scan is investigation of choice because of its accuracy in detecting the lesion $[3,7,15,18]$.

We have two treatment options conservative and operative. Conservative treatment relieves pain in some cases of osteoid osteoma and it consists of giving NSAID for longer period of time. The complete surgical excision is the treatment of choice to prevent the local recurrence [20]. Although the ribs are easily accessed, the reported lengths of en bloc resection of the nidus ranged from 5 to $9.5 \mathrm{~cm}$, which is significantly wider than the size of the nidus, that have led to varying reports of functional impairments [3,5-7]. Here we shall discuss about the importance of the image intensifier or skeletal scintigraphy in accurately localising the lesion and leading to minimal excision, instead of a wide local excision.

As per the available literature of the 15 cases of rib osteomas reported so far, we have come to the following consensus [3-16] as in Table 1.

\begin{tabular}{|c|c|c|c|c|c|c|}
\hline Year of study & Authors & Scintigraphy & $\begin{array}{l}\mathrm{C} \text { arm image } \\
\text { intensifier }\end{array}$ & CT Scan & $\begin{array}{l}\text { No used (C arm/ } \\
\text { scintigraphy) }\end{array}$ & No data \\
\hline 2018 & Nagre S W & - & - & - & Yes & Used intra opt Xray of rib \\
\hline 2015 & Deng et al. & Yes & Yes & Yes & - & - \\
\hline 1983 & Kehl et al. & Yes & Yes & Yes & - & - \\
\hline 1984 & McGuire et al. & - & - & Yes & - & Yes \\
\hline 1988 & Mehdian et al. & Yes & No & Yes & - & - \\
\hline 1992 & Veluvolu et al. & Yes & No & Yes & - & - \\
\hline 1958 & Mauer et al. & - & - & Yes & Yes & - \\
\hline 1986 & Lynch et al. & - & - & Yes & - & Yes \\
\hline 1987 & Nelson et al. & Yes & - & Yes & - & - \\
\hline 1989 & Kozlowski et al. & - & - & Yes & - & Yes \\
\hline 1991 & Cossetto et al. & Yes & Yes & Yes & - & - \\
\hline 1993 & Hoeffel et al. & - & - & Yes & - & Yes \\
\hline 1996 & McDermott et al. & Yes & - & Yes & - & - \\
\hline 1996 & Kargar et al. & - & - & Yes & Yes & - \\
\hline 2012 & Pirayesh et al. & Yes & - & Yes & - & - \\
\hline
\end{tabular}

As per the above table, a total of 8 authors used bone scintigraphy; of which Pirayesh, et al. used bone scintigraphy pre, intra as well as post operatively [16]. A total of 3 authors used both intra operative $C$ arm image intensifier as well as pre-operative skeletal scintigraphy $[3,4,8]$. C arm was used by 3 authors, but that was always in combination with the skeletal scintigraphy [3,4,12]. No localising diagnostic modality was used by 3 authors [8,15]. Pre-operative CT imaging was used by all authors [3-16]. No data was available in case of 4 reports $[5,9,11,13]$. In the case reported by Veluvolu, et al. CT scan had missed the lesion pre operatively [7], that later had to be confirmed by scintigraphy. 
The limited data available online shows that pre-operative skeletal scintigraphy, first described in 1980 by Rinsky, et al. [17], is the most relied modality of investigation that authors worldwide have resorted to in order to localise the nidus, and accordingly reduce the amount of material resected. Although some authors have reported the importance of CT scan as being the preferred imaging modality $[3,7,15,18]$, yet there has been a single instance in which the lesion has been missed entirely by CT scan [7]. Intra operative $\mathrm{C}$ arm image intensifier was always used in combination with pre-operative skeletal scintigraphy, but never in an isolated fashion $[3,4,12]$. This shows the growing reliance of authors on the efficacy of pre-operative skeletal scintigraphy, while intra operative $\mathrm{C}$ arm imaging still remains as a guiding factor for surgeons inside the operating room.

As far as our case is concerned, we are in the league of 2 previous authors who have attempted to resect the lesion with the guidance of only computed tomography $[8,15,20]$; though we have been able to resect the tumour with negative margins, yet we had to do an extended resection, in the absence of intra operative guidance.

Most probable causes for requiring extended resection in our case was

- Wrong interpretation by the radiologist about the site of lesion

- Wrong interpretation by the surgeon about the site of lesion

We are keeping the readers in dilemma about why we required the extended resection because the purpose of this paper is to impart in surgeons mind that the intraopt localization of $\mathrm{OO}$ is must to prevent further problems to patients as well as surgeons.

\section{Conclusions}

We feel that more comprehensive data regarding the efficacy and reliability of skeletal scintigraphy and intra operative $\mathrm{C}$ arm imaging needs to be published, with a comparison of both with computed tomography. This data might in future establish skeletal scintigraphy, with or without the associated intra operative $\mathrm{C}$ arm image intensifier, as the default and most preferred diagnostic modality for this rare tumour. It was always better to use these modalities intraoperatively to prevent morbidity to patient as well as to the surgeon. So our conclusion was - use any of available modality intraoperatively was compulsory.

\section{References}

1. Jaffe HL (1935) Osteoid osteoma. A benign osteoblastic tumor composed of osteoid and atypical bone. Arch Surg 31: 709-28.

2. Unni KK (1996) Osteoid osteoma. In: Dahlin's bone tumors: general aspects and data on 11,087 cases. 5th edition. Lippincott-Raven, Philadelphia, PA, 121 130.

3. Zhiping Deng, Yi Ding, Lin Hao, Fajun Yang, Lihua Gong, et al. (2015) Osteoid osteoma of the rib: a report of two cases. Oncol Lett 9: 1857-60.

4. Kehl DK, Alonso JE, Lovell WW (1983) Scoliosis secondary to an osteoid-osteoma of the rib. A case report. J Bone Joint Surg Am 65: 701-3.

5. Nagre SW, Bhosle KN, Gawali R, Ravikumar V (2017) Innovative use of contegra valved conduit in left iliocaval stent thrombosis. Indian J Thorac Cardiovasc Surg 1-4.

6. Mehdian H, Summers B, Eisenstein S (1988) Painful scoliosis secondary to an osteoid osteoma of the rib. Clin Orthop Relat Res 230: 273-6.

7. Nagre SW (2016) Hurdles for Starting Ministernotomy Aortic Valve Replacement Program. J Cardiovasc Med Cardiol 3: 035-7.

8. Mauer I (1958) Osteoid osteoma of the 12th rib; resection under local anesthesia; a case report. Mil Med 122: 194.

9. Nagre SW, Bendre S (2016) New four patch repair [Modified Brom's] technique for supravalvular aortic stenosis. Journal of Cardiovascular Disease Research 7: 39-42.

10. Nelson MC, Brower AC, Ragsdale BD (1987) Case report 448. Osteoid osteoma of left 6th rib with inflammatory reaction in the adjacent pleura and hyperostosis of the adjacent ribs. Skeletal Radiol 16: 601-3.

11. Nagre SW, Bhosle KN, Bendre S Vignesh R (2017) Surgical Management of Medium to Large Size Pulmonary AV Malformations- A Case Series. J Clin Respir Dis Care 3: 129 .

12. Cossetto D, Cummine J (1991) Rapidly growing twelfth rib osteoid osteoma. Aust NZ J Surg 61: 862-4.

13. Nagre SW (2017) Mobile Left Atrial Mass -Clot or Left Atrial Myxoma. J Cardio Dis Res 8: 31-4.

14. McDermott MB, Kyriakos M, McEnery K (1996) Painless osteoid osteoma of the rib in an adult. A case report and a review of the literature. Cancer 77: 1442-9. 15. Nagre SW, Nagre MS (2015) Observational Study of Surgical Closure of Ostium Primum Atrial Septal Defect in Thirty Paediatric Patients. Ann Woman Child Health 1: 1-4

16. Pirayesh E, Amoui M (2012) A rare presentation of osteoid osteoma in a rib and unexpected "double density sign": A case report and review of literature Iran. J Radiat Res 10: 197-99.

17. Suraj Wasudeo Nagre (2015) Surgical removal of embolised atrial septal defect device from pulmonary artery. J Thorac Cardio Surg 150: e55-7.

18. Touraine S, Emerich L, Bisseret D, Genah I, Parlier-Cuau C, et al (2104) Is pain duration associated with morphologic changes of osteoid osteomas at CT? Radiology 271: 795-804.

19. Nagre SW, Bhosle, KN, Shaikh A, Ravikumar V (2018) Pleuropulmonary blastoma-a case report and review of literature. Indian J Thorac Cardiovasc Surg 34: 72.

20. Mizuno S, Anazawa U, Hotta H, Asano N, Susa M, Miyauchi J, et al. (2015) A Rare Case of an Osteoid Osteoma of the Rib Treated under Computed Tomography Guidance: A Case Report and Review of the Literature. Case Rep Oncol 8: 509-14. 


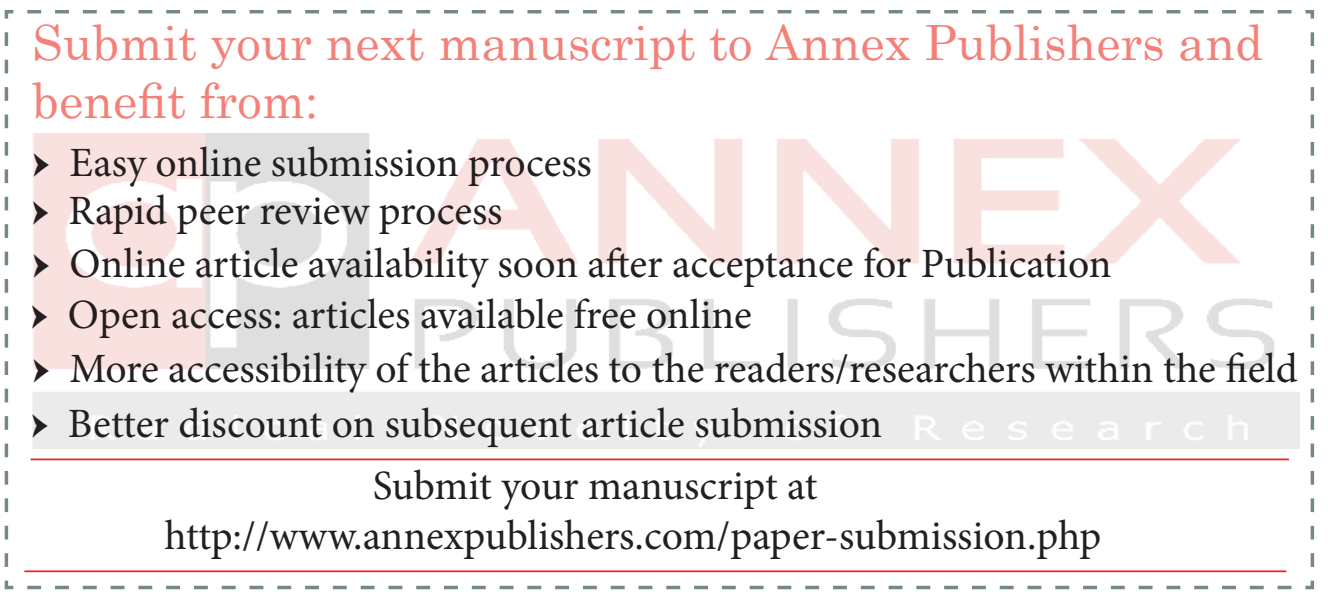

